\title{
Acoustic Analysis of an Exhaust MANIFOLD by INDIRECT Boundary Element Method
}

\author{
R. Citarella ${ }^{*}$ and M. Landi
}

Department of Industrial Engineering, University of Salerno, Fisciano (SA), Italy

\begin{abstract}
The present work is aimed at the development of a numerical procedure, based on the usage of the Boundary Element Method (BEM) as implemented in the software LMS Virtual.Lab, for the vibro-acoustics analysis of an exhaust manifold. The manifold vibrations are induced by two different ways: engine vibrations (transmitted to the manifold surfaces) and turbulences generated by the air flow in the exhaust system. The indirect BEM (IBEM), with a variational solution algorithm, is adopted to assess the exhaust manifold acoustic radiation. The modal analysis of the acoustic cavity is realized by the Finite Element Method (FEM) and the corresponding eigenfrequencies compared with those obtained by an IBEM forced response analysis and by experimental measurement. Experimental acoustic pressures at the manifold inlet and outlet are measured in anechoic room in order to compare with corresponding numerical predictions and assess the accuracy level obtained.
\end{abstract}

Keywords: Acoustic analysis, exhaust manifold, experimental measurements, FEM, IBEM, modal analysis.

\section{INTRODUCTION}

Nowadays, one of the most valuable criteria for vehicle quality assessment is based on acoustic emission levels: a car is judged comfortable also depending on the noise level transmitted inside. Consequently there is a general attention to design criteria aimed at improving the structural-acoustic behavior, in such a way to withstand the increasingly restrictive ergonomic standard. A design approach based on experimental and numerical procedures, enables the prediction of noise emissions and the correlation with the structural vibration source. The following step is the redesign of those components responsible for intolerable emissions, without the need for an extensive and expensive prototyping effort [1].

\subsection{BEM/FEM or FEM/FEM}

For coupled structure-acoustic problems one can use acoustic boundary elements or acoustic finite elements. There are pros and cons for both methods, but generally coupled FEM/FEM should be used for internal problems, and coupled BEM/FEM should be used for external problems with unbounded regions, i.e. infinite regions. Even if a BEM/FEM model usually have less elements than a corresponding FEM/FEM model it does not mean that the $\mathrm{BEM} / \mathrm{FEM}$ model results in higher computational efficiency. Since the influence matrices in a BEM model are fully populated, and not banded as the stiffness matrix for a FEM model, they can take a considerable amount of time to calculate. So, for an internal problem a FEM/FEM model is often quicker. For external unbounded problems BEM/FEM comes to its full right, since boundary elements satisfy the Sommerfeld radiation condition and therefore can handle

*Address correspondence to this author at the Department of Industrial Engineering, University of Salerno, Fisciano (SA), Italy; Tel: +39089964111; Fax: +39089968781; E-mail: rcitarella@unisa.it infinite regions. An unbounded region is difficult to model with FEM/FEM since the problem region must be demarcated before it is divided into elements. The demarcation creates a boundary which boundary conditions are hard to find. With improper boundary values the solution will be disturbed by the demarcation.

Consequently, even if the exclusive usage of FEM to work out acoustic problems is still popular [2-4], nowadays, the most efficient approach to study the car vibroacoustic problems is based on the coupled usage of Finite Element Method (FEM) for vibration analysis and Boundary Element Method for acoustic analysis [5-9]. The possibility offered by BEM to reduce the dimensionality of the meshing domain is highly appreciated when considering the complex geometry of the car components; moreover, as previously said, BEM performs better for exterior problems (e.g., radiation from a component in an infinite domain). In both BEM and FEM methodologies acoustic models can be developed using general purpose modelers through the link to CAD provided, but with BEM the boundary mesh generation is very simple compared with volume mesh generation and can be completed automatically with little user interaction.

This work is aimed at setting up and validate a numerical procedure for a vehicle component acoustic radiation assessment, by a synergetic use of Boundary Element (BE) and Finite Element (FE) methods. In particular such procedure is applied to predict the acoustic radiation of an exhaust manifold, whose acoustic properties were previously assessed by experimental measurements in an anechoic room. The manifold cavity modal behavior is assessed by an FEM modal analysis and the transmitted noise field calculated by a BEM analysis in an integrated virtual environment provided by LMS Virtual.Lab.

The aforementioned virtual procedure, when calibrated, should allow to simulate the tentative design solutions for an active $[10]$ or passive $[11,12]$ reduction of the structural 
noise transmitted inside the car cabin, avoiding the need for expensive experimental tests.

A critical part of this kind of problems is related to the separation between the structural noise contribution, (e.g. transmitted by the power train and suspension system) and the aerodynamic noise contribution (e.g. due to sound pressure level below the car body, generated by the tires [13, 14]).

\section{PROBLEM DESCRIPTION}

\subsection{Exhaust Manifold}

The car component under study is an exhaust manifold (Fig. 1), whose role is to convey the exhaust gas towards the exhaust apparatus made of catalytic converter, muffler, final resonator and exhaust pipes (Fig. 2).

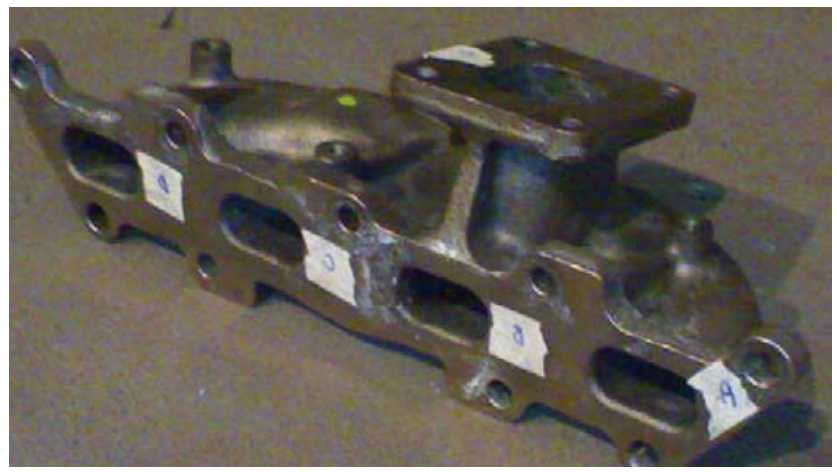

Fig. (1). Car exhaust manifold.
When considering the cabin noise, the exhaust manifold is one of the most critical components and consequently a strong effort in the design phase is devoted to its vibroacoustics optimization.

The generated noise is mainly due to engine vibrations, transmitted to the exhaust manifold surfaces, and to air flow in the exhaust system (the exhaust valve closing and opening produces pressure waves in the pipes responsible for the manifold vibrations). Another relevant contribution, not considered here, is the high frequency aerodynamic noise produced by the turbulence of the exhaust gas.

\subsection{Experimental Measurements}

Experimental acoustic pressures are measured in the anechoic room, taking advantage of the wall absorbing properties and consequent "free field" environment. The first step is the test set-up by assembly of manifold, microphones and acoustic source as in Fig. (3): an equipment calibration is needed before to start with the acoustic excitation of the analyzed component; finally the sound pressures are recorded in microphone positions. The experimental measurements are elaborated by the LMS Test.Lab software.

The two capacitor microphones adopted are of the kind "free-field" (0.5 inches), with a sensitivity equal to 49.8 $\mathrm{mV} / \mathrm{Pa}$, and with amplifier set-in (actually for the peculiar kind of acoustic field a normal pressure microphone would provide the best results).

One microphone (in the following called "Ref") is located at the manifold runner, close to the source nozzle,

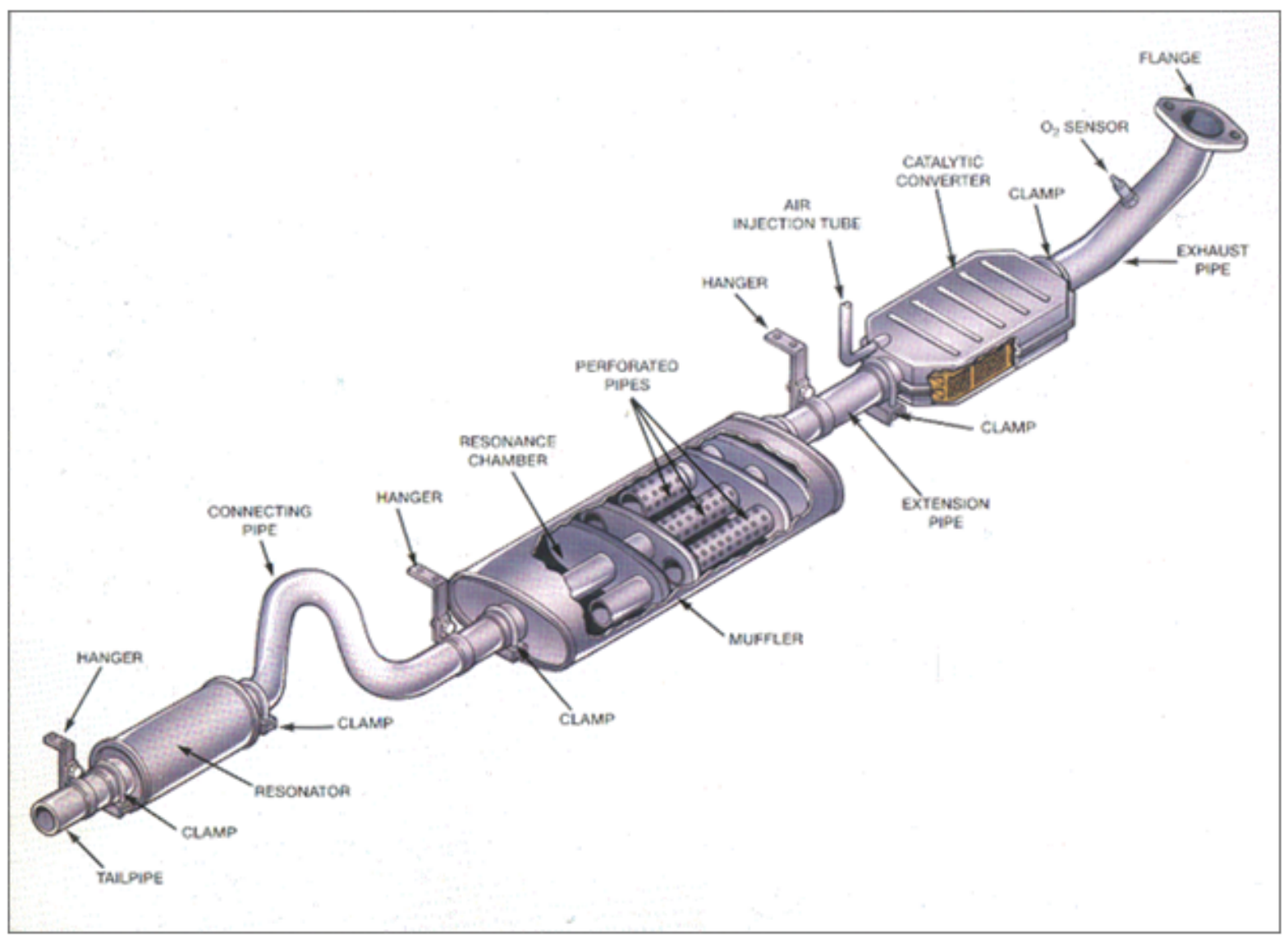

Fig. (2). Car exhaust system. 

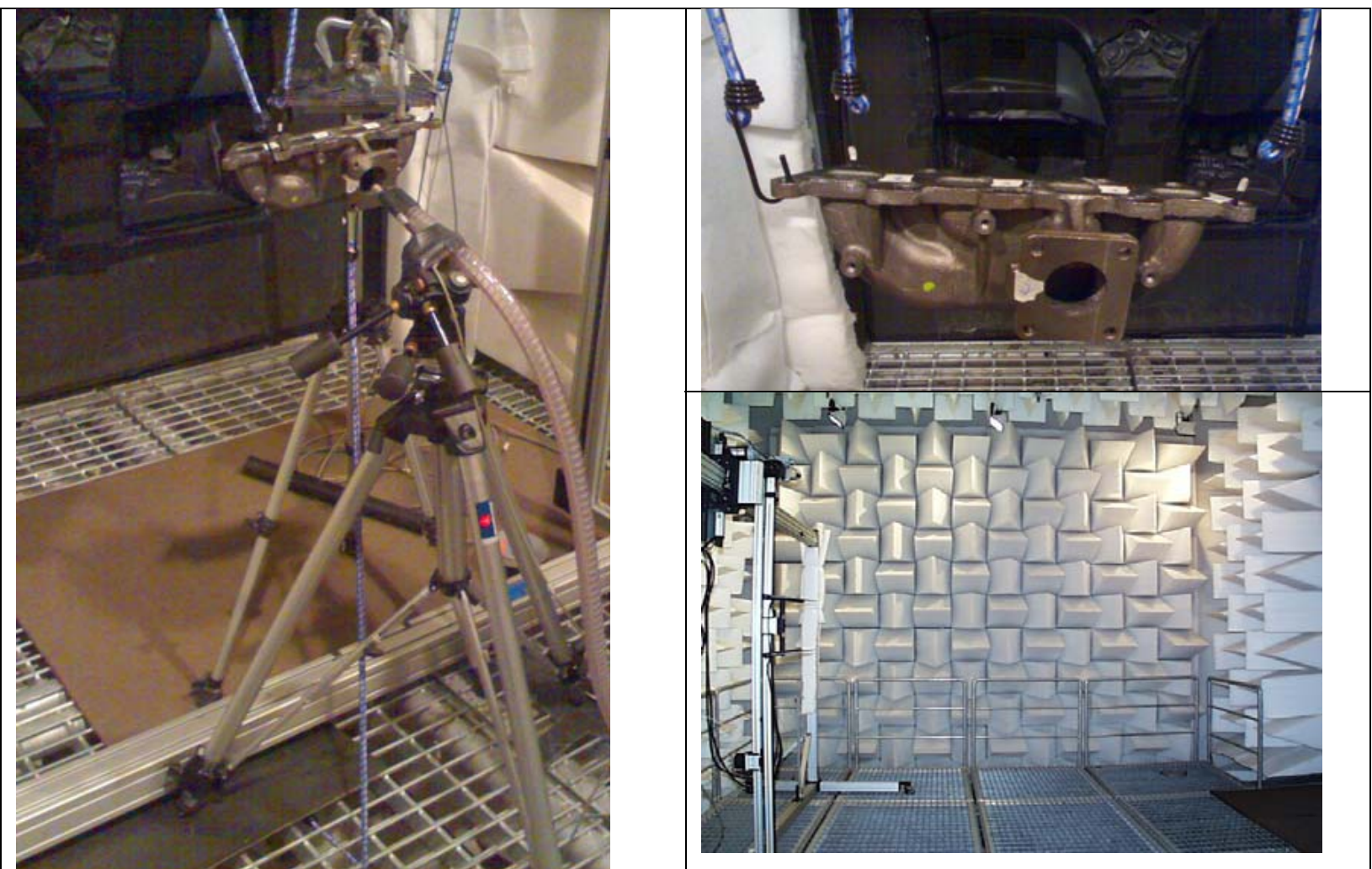

Fig. (3). Experimental set up in anechoic room.

and the other at the manifold inlet in such a way to measure the noise transmitted through the manifold (Figs. 3, 4).

The adopted acoustic source (Fig. 5) is a mid to high frequency volume acceleration sound source (LMS EMHFVVS); it can span a frequency range between 200 and $10000 \mathrm{~Hz}$. The noise is generated in a high pressure driver and transferred by a flexible pipe (whose length is $4.25 \mathrm{~m}$ ) to a final nozzle (with diameter equal to $27 \mathrm{~mm}$ and length equal to $45 \mathrm{~mm}$ ). All the devices are connected to the interface LMS SCADAS III, that drive the source, through the channel QDAC, and proceed through the channel PQA for the microphone pressure acquisition. The interface is connected to a PC Windows ${ }^{\circledR}$-based and the signals are elaborated by the software LMS Test. Lab, that is also used to drive the source, make the signal windowing (i.e. to avoid leakage phenomena) and avoid aliasing problems.

Four different test were realized by placing the microphone "Resp" alternatively on each "runner" (A-D) and keeping fixed the microphone "Ref" position at the manifold exit "R" (Fig. 4).

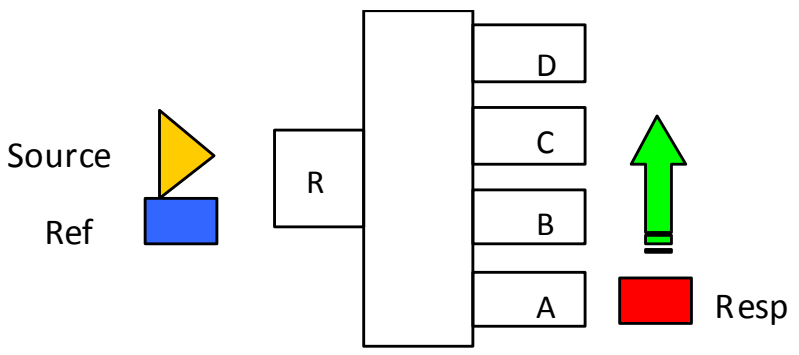

Fig. (4). Test set-up, with highlight of the "moving" microphone ("Resp").

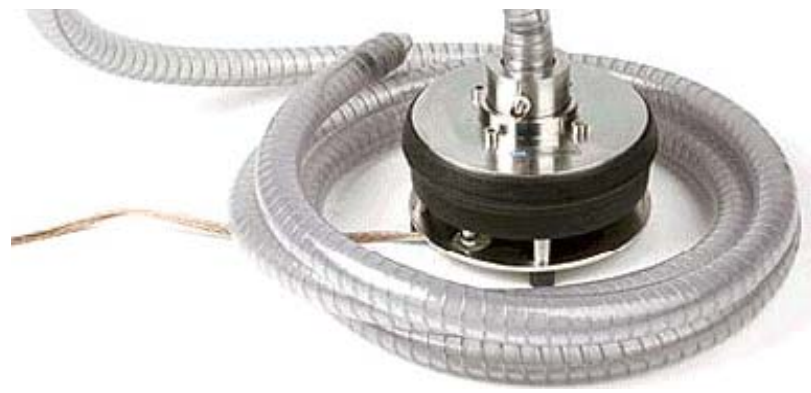

Fig. (5). Acoustic source.

\section{ACOUSTIC ANALYSIS BY BOUNDARY ELEMENT METHOD}

\subsection{Helmhotz Equation}

The basic equation for acoustic wave propagation through an elastic medium is the linear wave equation:

$\nabla^{2} u=\frac{1}{c^{2}} \frac{\partial^{2} u}{\partial t^{2}}+b$

where $u(x, t)$ is the velocity potential, $\mathrm{c}$ is the speed of sound, $b(x, t)$ is the sound source, $x$ and $t$ are the position and time variables. Assuming that the problem is time harmonic, Eq. (1) can be transferred to the frequency domain so as to obtain the Helmhotz equation:

$$
\nabla^{2} u+k^{2} u=b
$$

where $k=\omega / c$ is the wave number and $\omega=2 \pi f$ the angular frequency. 


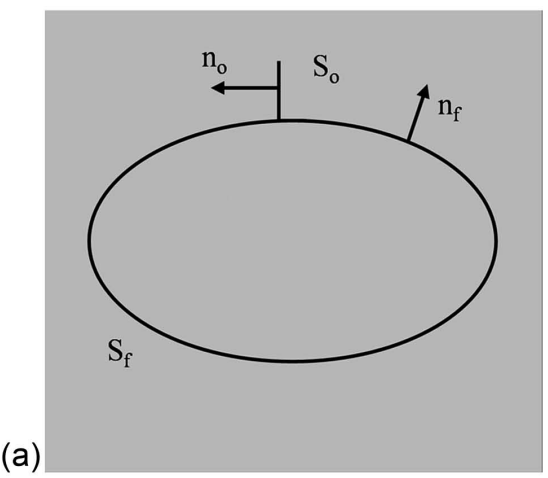

Figs. (6a-b). Indirect BEM.

\subsection{Indirect BEM (IBEM)}

The simplest way to derive the indirect boundary integral formulation of the Helmholtz equation employs the approach of applying the direct formulation to an acoustic domain where the fluid is inside as well as outside the bounding surface $\mathrm{S}$ (Fig. 6).

Consider for the general case a closed surface $S_{\mathrm{f}}$ with an open extension $\mathrm{S}_{\mathrm{o}}$ (Fig. 6a). The entire space is the domain of interest V. V consists of two sub-domains, the interior and the exterior one, each bounded by a closed surface (Fig. 6b). Normal vectors in Fig. (6a) define the orientation of the surfaces $S_{f}$ and $S_{0}$. The orientation of the exterior normal vectors in Fig. (6b) is chosen such that Green's identity and the Helmholtz integral equation are valid. Consider the latter for a point $\mathrm{P}$ located anywhere in the field but neither on $\mathrm{S}_{\mathrm{f}}$ nor on $\mathrm{S}_{\mathrm{o}}$. Thus, from the Helmholtz integral equation, written in terms of pressure and normal velocity

$$
p\left(\vec{r}_{p}\right)=-\oint_{S}\left(p \partial_{n} G+i \rho \omega G v_{n}\right) d S-\int_{V} G q d V
$$

neglecting body sources, one obtains

$$
\begin{aligned}
& p\left(\vec{r}_{p}\right)+\int_{S_{f_{e}}}\left(p \partial_{n_{f_{e}}} G+i \rho \omega G v_{n_{f_{e}}}\right) d S+\int_{S_{f_{i}}}\left(p \partial_{n_{f_{i}}} G+i \rho \omega G v_{n_{f_{i}}}\right) d S+ \\
& \int_{S_{o_{g}}}\left(p \partial_{n_{o_{g}}} G+i \rho \omega G v_{n_{o_{g}}}\right) d S+\int_{S_{o_{d}}}\left(p \partial_{n_{o_{d}}} G+i \rho \omega G v_{n_{o_{d}}}\right) d S=0
\end{aligned}
$$

However, it is known that:

$$
\begin{aligned}
& \cdot \mathrm{S}_{\mathrm{og}}=\mathrm{S}_{\mathrm{od}}=\mathrm{S}_{\mathrm{o}} \text { and } \mathrm{S}_{\mathrm{fe}}=\mathrm{S}_{\mathrm{fi}}=\mathrm{S}_{\mathrm{f}} \\
& \cdot \mathrm{n}_{\mathrm{og}}=-\mathrm{n}_{\mathrm{o}} \text { and } \mathrm{n}_{\mathrm{od}}=\mathrm{n}_{\mathrm{o}} \\
& \cdot \mathrm{n}_{\mathrm{fe}}=-\mathrm{n}_{\mathrm{f}} \text { and } \mathrm{n}_{\mathrm{fi}}=\mathrm{n}_{\mathrm{f}} .
\end{aligned}
$$

This yields:

$$
\begin{aligned}
& p\left(\vec{r}_{p}\right)+\int_{S_{f}}\left(p_{f_{e}}\right.\left.-\left(\partial_{n_{f}} G\right)+i \rho \omega G\left(-v_{n_{f_{e}}}\right)\right) d S \\
&+\int_{S_{f}}\left(p_{f_{i}} \partial_{n_{f}} G+i \rho \omega G v_{n_{f}}\right) d S+ \\
& \int_{S_{o}}\left(p_{o_{g}}\left(-\partial_{n_{o}} G\right)\right.\left.+i \rho \omega G\left(-v_{n_{o_{g}}}\right)\right) d S \\
&+\int_{S_{o}}\left(p_{o_{d}} \partial_{n_{o_{d}}} G+i \rho \omega G v_{n_{o_{d}}}\right) d S=0
\end{aligned}
$$

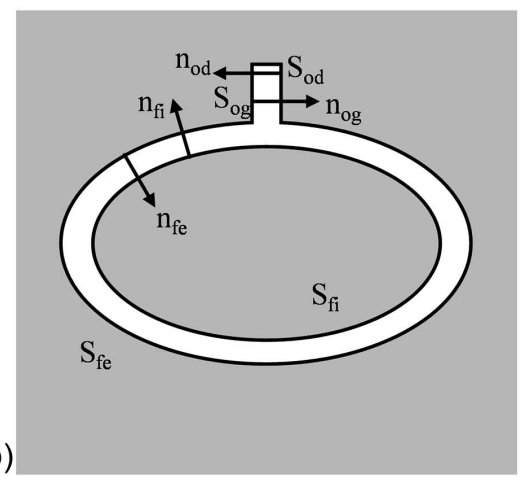

Some manipulations and rearrangement of terms lead to

$$
\begin{aligned}
& p\left(\vec{r}_{p}\right)=\int_{S_{f}}\left(\left(p_{f_{e}}-p_{f_{i}}\right) \partial_{n_{f}} G+i \rho \omega G\left(v_{n_{f}}-v_{n_{f_{i}}}\right)\right) d S+ \\
& \int_{S_{o}}\left(\left(p_{o_{g}}-p_{o_{d}}\right) \partial_{n_{o}} G+i \rho \omega G\left(v_{n_{o_{g}}}-v_{n_{o_{d}}}\right)\right) d S
\end{aligned}
$$

Now define $\sigma$ to be the velocity difference across the surfaces and $\mu$ the pressure difference between each side of the boundary (in analogy to electromagnetism, $\sigma$ is called the "single layer potential" and $\mu$ the "double layer potential") and rewrite the previous equation to obtain

$$
\begin{aligned}
& p\left(\vec{r}_{p}\right)=\int_{S=S_{f}+S_{o}}\left(\mu \partial_{n} G+i \rho \omega G \sigma\right) d S \\
& p\left(\vec{r}_{p}\right)^{ \pm}= \pm c_{p} \mu_{p}+\int_{S}\left(\mu \partial_{n} G+i \rho \omega G \sigma\right) d S \\
& v_{n}\left(\vec{r}_{p}\right)^{ \pm}= \pm c_{p} \mu_{p}+\frac{i}{\rho \omega} \int_{S}\left(\mu \frac{\partial^{2} G}{\partial n \partial n_{p}}+i \rho \omega \frac{\partial G}{\partial n_{p}} \sigma\right) d S
\end{aligned}
$$

The integral term

$$
\int_{S} \mu(Q) \frac{\partial^{2} G}{\partial n \partial n_{p}} d S
$$

is singular and its Hadamard finite part must be taken [15]:

$$
\int_{S} \mu \frac{\partial^{2} G}{\partial n \partial n_{p}} d S=\lim _{p \rightarrow p_{0} e S} \frac{\partial}{\partial n_{p}} \int_{S} \mu \frac{\partial G}{\partial n} d S
$$

The integral term

$$
\int_{S} \sigma \frac{\partial G}{\partial n_{p}} d S
$$

is also singular. Its Cauchy principal value must be considered [16]:

$\int_{S} \sigma \frac{\partial G}{\partial n_{p}} d S=\lim _{\varepsilon \rightarrow 0} \int_{S-\Sigma} \sigma \frac{\partial G}{\partial n_{p}} d S$

where $\Sigma$ is the neighborhood with radius $\varepsilon$ of $\mathrm{P}$.

The indirect formulation [17] allow the contemporary resolution of the internal and external problem so it is particularly useful when considering an open vibrating domain 
(like in our case). As a matter of fact, differently from the direct approach in which the problem variables are defined only on one side of the domain boundary, the indirect representation make usage of the layer potentials that are the differences between internal and external pressures (double layer potentials) or between the pressure gradients (single layer potentials):

$$
\mu=p^{+}-p^{-} \quad \sigma=\frac{\partial p^{+}}{\partial n}-\frac{\partial p^{-}}{\partial n}
$$

where $\mathrm{p}+$ and $\mathrm{p}$ - are the external and internal pressures (Fig. 6c).

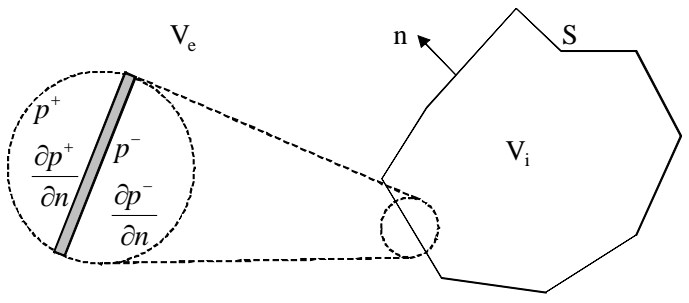

Fig. (6c). Indirect BEM.

The particle vibration velocity is calculated in a post processing phase as a function of the layer potentials.

In a well posed problem in each point of the surface one of the following boundary conditions must be specified:

- pressure,

- normal velocity,

- surface impedance, providing a relation between the two aforementioned variables.

The first step is then the calculation of unknown layer potentials through a solution scheme based on a variational formulation [18].

\subsection{Variational Scheme - Neumann Problem}

Since it is the most important boundary condition, the variational scheme for the Neumann problem will now be discussed in depth. The treatment of other boundary conditions may be found, e.g., in Hamdi [19]. Consider the indirect boundary integral equation for velocity:

$v_{n}^{ \pm}\left(\vec{r}_{p}\right)= \pm c_{p} \sigma\left(\vec{r}_{p}\right)+$

$\frac{i}{\rho \omega} \int_{S}\left(\mu\left(\vec{r}_{Q}\right) \frac{\partial^{2} G\left(\vec{r}_{p}, \vec{r}_{Q}\right)}{\partial n_{Q} \partial n_{p}}+i \rho \omega \frac{\partial G\left(\vec{r}_{p}, \vec{r}_{Q}\right)}{\partial n_{p}} \sigma\left(\vec{r}_{Q}\right)\right) d S\left(\vec{r}_{Q}\right)$

In the case of a Neumann problem $(\mathrm{vn} \pm=\mathrm{vn} \rightarrow \sigma=0)$, this equation becomes:

$\bar{v}_{n}\left(\vec{r}_{p}\right)=\frac{i}{\rho \omega} \int_{S} \mu\left(\vec{r}_{Q}\right) \frac{\partial^{2} G\left(\vec{r}_{p}, \vec{r}_{Q}\right)}{\partial n_{Q} \partial n_{p}} d S\left(\vec{r}_{Q}\right)$

The solution to eqn.16 minimizes the functional:

$$
\begin{array}{r}
J=\frac{1}{2} \int_{S} \int_{S} \mu\left(\vec{r}_{p}\right) \mu\left(\vec{r}_{Q}\right) \frac{\partial^{2} G\left(\vec{r}_{p}, \vec{r}_{Q}\right)}{\partial n_{p} \partial n_{Q}} d S\left(\vec{r}_{p}\right) d S\left(\vec{r}_{Q}\right) \\
-\int_{S} \bar{v}_{n}\left(\vec{r}_{p}\right) \mu\left(\vec{r}_{p}\right) d S\left(\vec{r}_{p}\right)
\end{array}
$$

Replacing S by its discrete form, which is the set of boundary elements that completely covers $\mathrm{S}$, one obtains

$$
\begin{array}{r}
J=\frac{1}{2} \sum_{i} \sum_{j} \int_{S_{i}} \int_{S_{j}} \mu\left(\vec{r}_{p}\right) \mu\left(\vec{r}_{Q}\right) \frac{\partial^{2} G\left(\vec{r}_{p}, \vec{r}_{Q}\right)}{\partial n_{p} \partial n_{Q}} d S\left(\vec{r}_{p}\right) d S\left(\vec{r}_{Q}\right) \\
-\sum_{i} \int_{S_{i}} \vec{v}_{n}\left(\vec{r}_{p}\right) \mu\left(\vec{r}_{p}\right) d S\left(\vec{r}_{p}\right)
\end{array}
$$

Employing the discrete approximation for $\mu$ :

$$
\mu \cong \mu^{h}=\sum_{j} N_{j} \mu_{j}
$$

leads to

$$
\begin{array}{r}
J^{h}=\frac{1}{2} \sum_{i} \sum_{j} \int_{S_{i}} \int_{S_{j}} \sum_{k} \sum_{m} \mu_{k} \mu_{m} N_{k}\left(\vec{r}_{p}\right) N_{m}\left(\vec{r}_{Q}\right) \frac{\partial^{2} G\left(\vec{r}_{p}, \vec{r}_{Q}\right)}{\partial n_{p} \partial n_{Q}} \\
d S\left(\vec{r}_{p}\right) d S\left(\vec{r}_{Q}\right)-\sum_{i} \int_{S_{i}} \vec{v}_{n}\left(\vec{r}_{p}\right) \sum_{k} \mu_{k} N_{k}\left(\vec{r}_{p}\right) d S\left(\vec{r}_{p}\right)
\end{array}
$$

Similar to the formulation of the direct BEM, the nodal potential values are shifted in front of the integrals:

$$
\begin{array}{r}
J^{h}=\frac{1}{2} \sum_{i} \sum_{j} \sum_{k} \sum_{m} \mu_{k} \mu_{m} \int_{S_{i}} \int_{S_{j}} N_{k}\left(\vec{r}_{p}\right) N_{m}\left(\vec{r}_{Q}\right) \frac{\partial^{2} G\left(\vec{r}_{p}, \vec{r}_{Q}\right)}{\partial n_{p} \partial n_{Q}} \\
d S\left(\vec{r}_{p}\right) d S\left(\vec{r}_{Q}\right)-\sum_{i} \sum_{k} \mu_{k} \int_{S_{i}} \vec{v}_{n}\left(\vec{r}_{p}\right) N_{k}\left(\vec{r}_{p}\right) d S\left(\vec{r}_{p}\right)
\end{array}
$$

Finally, changing the order of summation gives:

$$
\begin{aligned}
& J^{h}=\frac{1}{2} \sum_{k} \sum_{m} \mu_{k} \mu_{m} \\
& {\left[\sum_{i} \sum_{j} \int_{S_{i}} \int_{S_{j}} N_{k}\left(\vec{r}_{p}\right) N_{m}\left(\vec{r}_{Q}\right) \frac{\partial^{2} G\left(\vec{r}_{p}, \vec{r}_{Q}\right)}{\partial n_{p} \partial n_{Q}} d S\left(\vec{r}_{p}\right) d S\left(\vec{r}_{p}\right)\right]} \\
& -\sum_{k} \mu_{k} \sum_{i} \mu_{k} \int_{S_{i}} \bar{v}_{n}\left(\vec{r}_{p}\right) N_{k}\left(\vec{r}_{p}\right) d S\left(\vec{r}_{p}\right)
\end{aligned}
$$

For ease of notation, define the following:

$$
\begin{aligned}
& a_{k m}=\sum_{i} \sum_{j} \int_{S_{i}} \int_{S_{j}} N_{k}\left(\vec{r}_{p}\right) N_{m}\left(\vec{r}_{Q}\right) \frac{\partial^{2} G\left(\vec{r}_{p}, \vec{r}_{Q}\right)}{\partial n_{p} \partial n_{Q}} d S\left(\vec{r}_{p}\right) d S\left(\vec{r}_{p}\right) \\
& b_{k}=\sum_{i} \int_{S_{i}} \vec{v}_{n}\left(\vec{r}_{p}\right) N_{k}\left(\vec{r}_{p}\right) d S\left(\vec{r}_{p}\right)
\end{aligned}
$$

The discrete functional may then be written as:

$$
J^{h}=\frac{1}{2} \sum_{k} \sum_{m} \mu_{k} \mu_{m} a_{k m}-\sum_{k} \mu_{k} b_{k}
$$

or in matrix form:

$$
J^{h}=\frac{1}{2} \mu^{T} A \mu-\mu^{T} b
$$

$\mathrm{J}_{\mathrm{h}}$ is a bilinear function of the unknown nodal potentials. Requiring $\mathrm{J}_{\mathrm{h}}$ to be stationary with respect to $\mu$ :

$$
\frac{\partial J^{h}}{\partial \mu}=0 \Rightarrow A \mu-b
$$


gives a system of equations $\mathbf{A} \boldsymbol{\mu}=\mathbf{b}$, which yields the unknown potentials $\mu$ (some practical implementation issues are found in [20]). It should be mentioned that the expressions for the coefficients of the matrix $\mathbf{A}$ includes a singular integral in $\left(1 / \mathrm{r}^{3}\right)$.

\section{IBEM ANALYSIS OF THE EXHAUST MANIFOLD WITH EXPLICIT ACOUSTIC SOURCE MODELING}

\subsection{Exhaust Manifold Model}

The starting point for the modeling phase is represented by the manifold FEM mesh (Fig. 7), obtained by the software HYPERMESH; such mesh, after a "skinning" process realized in Virtual Lab environment (in which also a mesh coarsening can be activated), provides the IBEM mesh of the enclosed fluid cavity (Fig. 8). The normal velocity on the boundary of the fluid cavity is equal to zero (the manifold wall vibrations are not considered here).

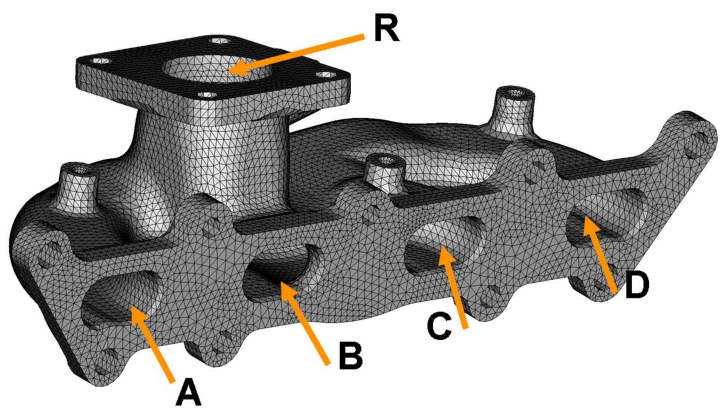

Fig. (7). Manifold FEM model.

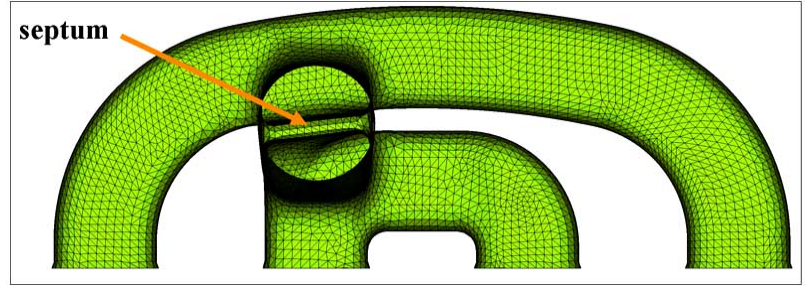

Fig. (8). Manifold cavity IBEM model.
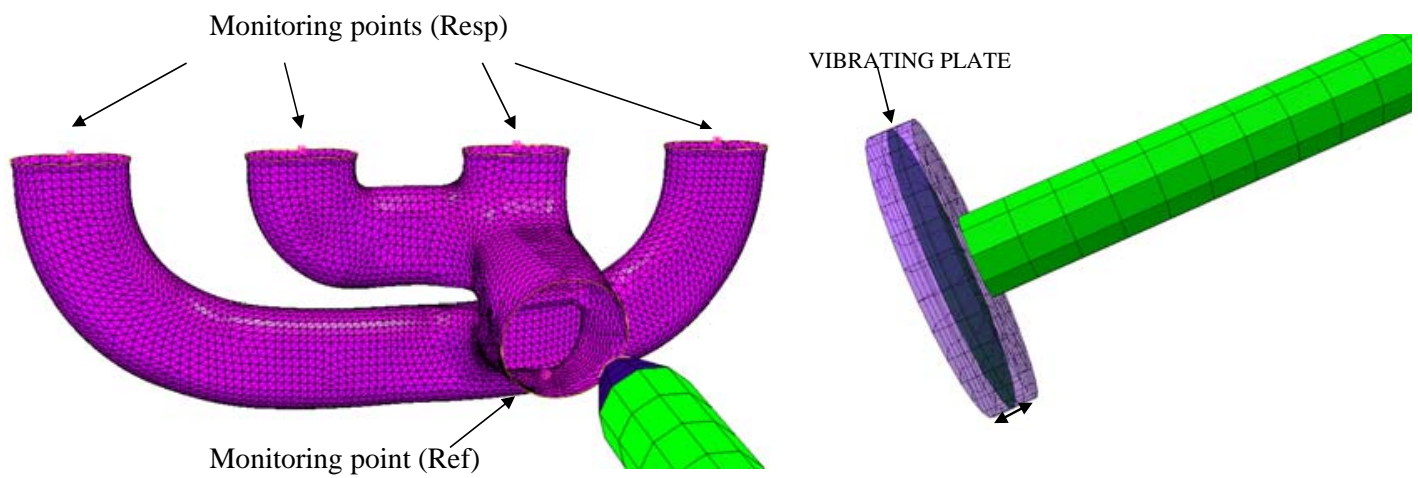

The acoustic source is modeled by a vibrating plate (the plate normal velocity is constant over the frequency range and act as a scale factor) and by a rubber tube connecting the source itself with the nozzle (Fig. 9).

The initial IBEM mesh is based on 12483 triangular quadratic elements (6 nodes), for an overall number of nodes equal to 25153 (this corresponds also to the number of dof's). After a convergence study it is possible to assess that the same mesh but with a lower polynomial order (linear elements) is sufficient to guarantee the needed accuracy (the Coarser Mesher utility is used to decrease the element polynomial order): in this way the overall number of nodes decreases to 6347 . If considering as a rule of thumb at least six linear elements per wave length, the latter mesh can be used up to a maximum frequency of $5000 \mathrm{~Hz}$.

Monitoring points, located in correspondence of the microphone positions, are introduced in the IBEM model in order to evaluate (by postprocessing) the numerical pressures (Fig. 9).

A boundary condition in terms of frequency independent impedance is applied on the rubber tube walls: only the real part is considered, with a value obtained by calibration from a simple test (described in the following) and equal to 200000 Rayl.

Such choice on the impedance value is prone to further improvements but the correct impedance characterization on the model surfaces is surely a very difficult and sensible aspect in the acoustic simulations [21, 22], asking for a preliminary experimental effort on the considered material.

\subsection{Tube Impedance Calibration Test}

In order to assess the impedance of the source rubber tube, a preliminary test (Fig. 10) is designed considering a simple metallic tube (Fig. 11) instead of the manifold. A "sweep" in the frequency range $250-1000 \mathrm{~Hz}$ is provided by the acoustic source with the pressure at the two microphones recorded and compared with the numerical pressures. The latter are calculated by an IBEM analysis (Fig. 12) choosing 
the rubber tube real impedance value $(Z=200000$ Rayl) that provides the best fit numerical-experimental results (Figs. $13,14)$.

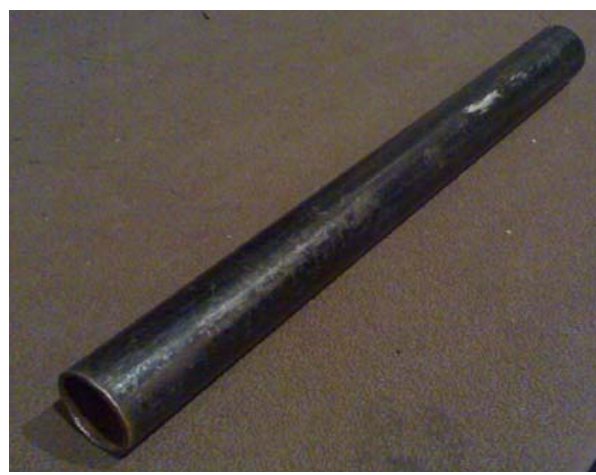

Fig. (11). Metallic tube adopted for the calibration test.

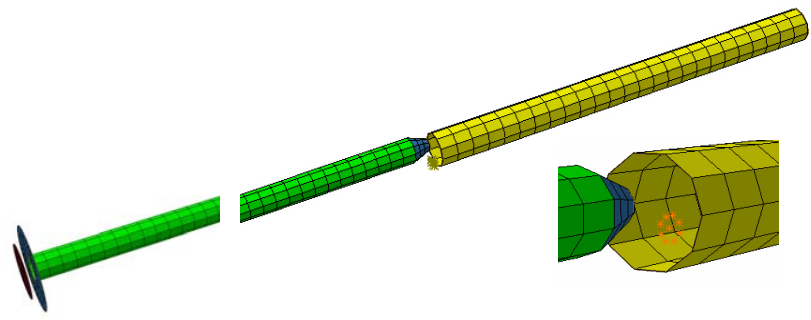

Fig. (12). IBEM model of source+rubber tube and metallic tube.

\subsection{Exhaust Manifold Results}

Once calibrated the rubber tube impedance $(Z=200000$ Rayl) it is possible to proceed with the numerical analysis on the manifold. The acoustic pressure is calculated in the range $900-2500 \mathrm{~Hz}$ with a frequency step for the numerical and experimental analysis respectively equal to $\Delta \mathrm{f}=2 \mathrm{~Hz}$ and $\Delta \mathrm{f}=1 \mathrm{~Hz}$, consequently 800 independent matrix resolution are necessary in the simulation; if a speed up of the solution phase is needed the Padè expansions can be activated [23].

Figs. (15-19) show the experimental and numeric acoustic pressure (expressed in $\mathrm{dB}$ ref $2 * 10^{-5}$ ) at the position " $R$ " and in correspondence of the four runner (A-D), in the frequency range $900-2500 \mathrm{~Hz}$. The cyclic fluctuation is due to the rubber tube modal behaviour: each peak is distant from the following $42 \mathrm{~Hz}$, that is also the first rubber tube resonance (and this phenomenon is clearly present also when considering the metallic tube, as visible in Figs. $(\mathbf{1 2}, \mathbf{1 3})$ ). Such periodic fluctuations can be smoothed by a moving average.

Moreover it is to be pointed out a sort of frequency shift between the numerical and experimental trend as due to numerical eigenfrequencies higher than those measured in anechoic room.

Figs. (20, 21) show respectively the experimental and numerical ratios between acoustic pressures at the four

Microphone Ref

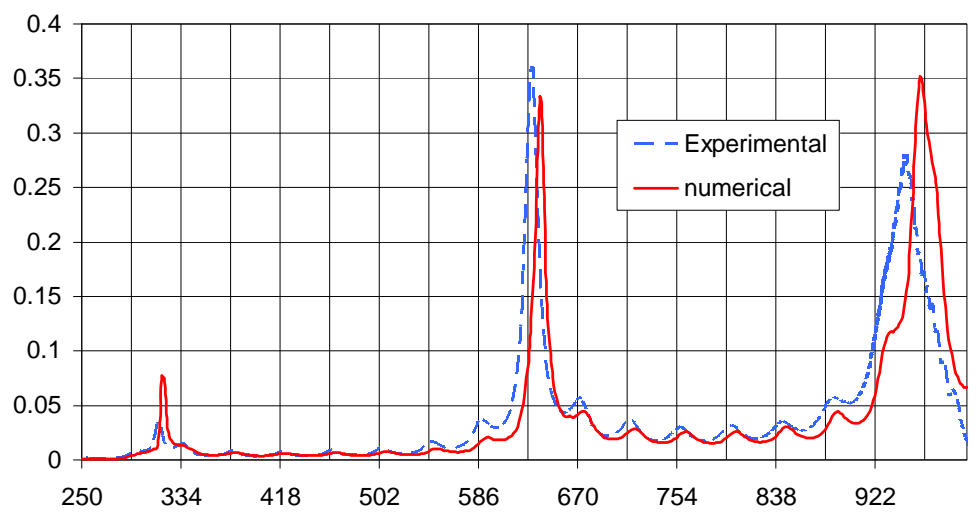

Fig. (13). Numerical (calculated with $Z=200000$ Rayl) and experimental pressure $[\mathrm{Pa}]$ at the microphone "Ref".

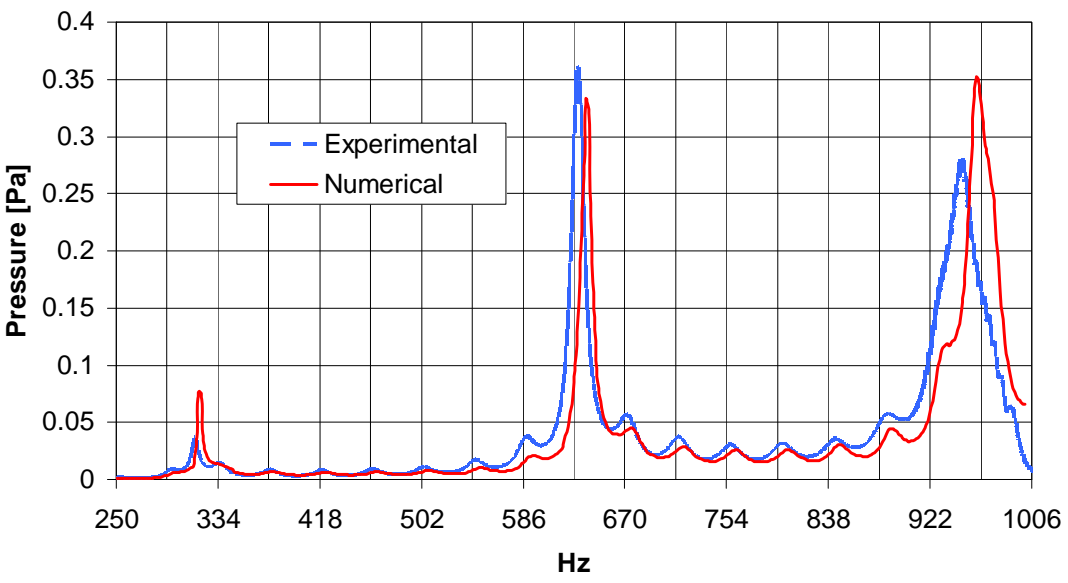

Fig. (14). Numerical ( $Z=200000$ Rayl) and experimental pressure at the microphone "Resp". 


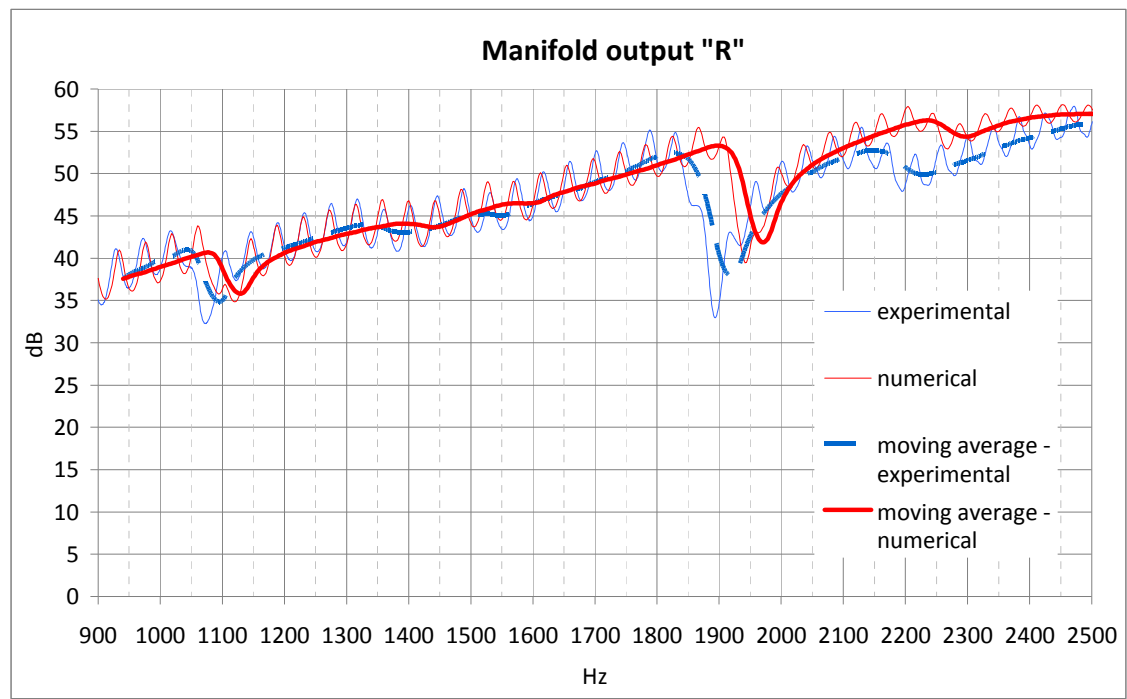

Fig. (15). Numerical and experimental acoustic pressure at the position "R" of the manifold.

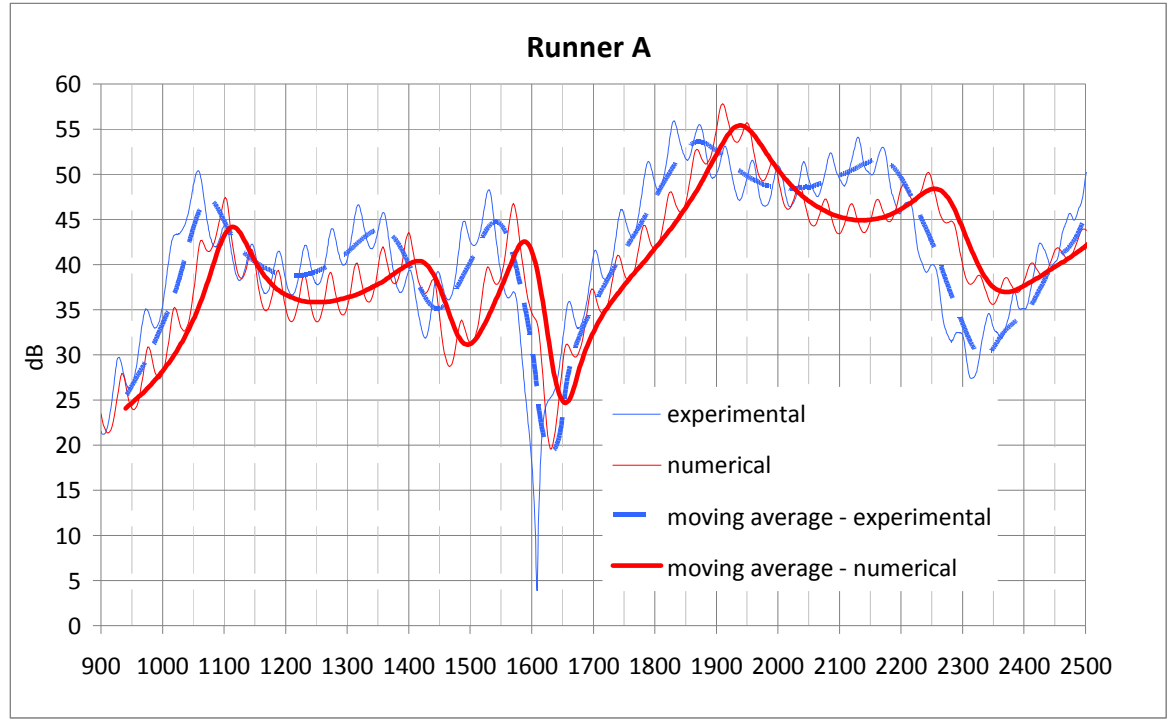

Fig. (16). Numerical and experimental acoustic pressure at the runner A of the manifold.

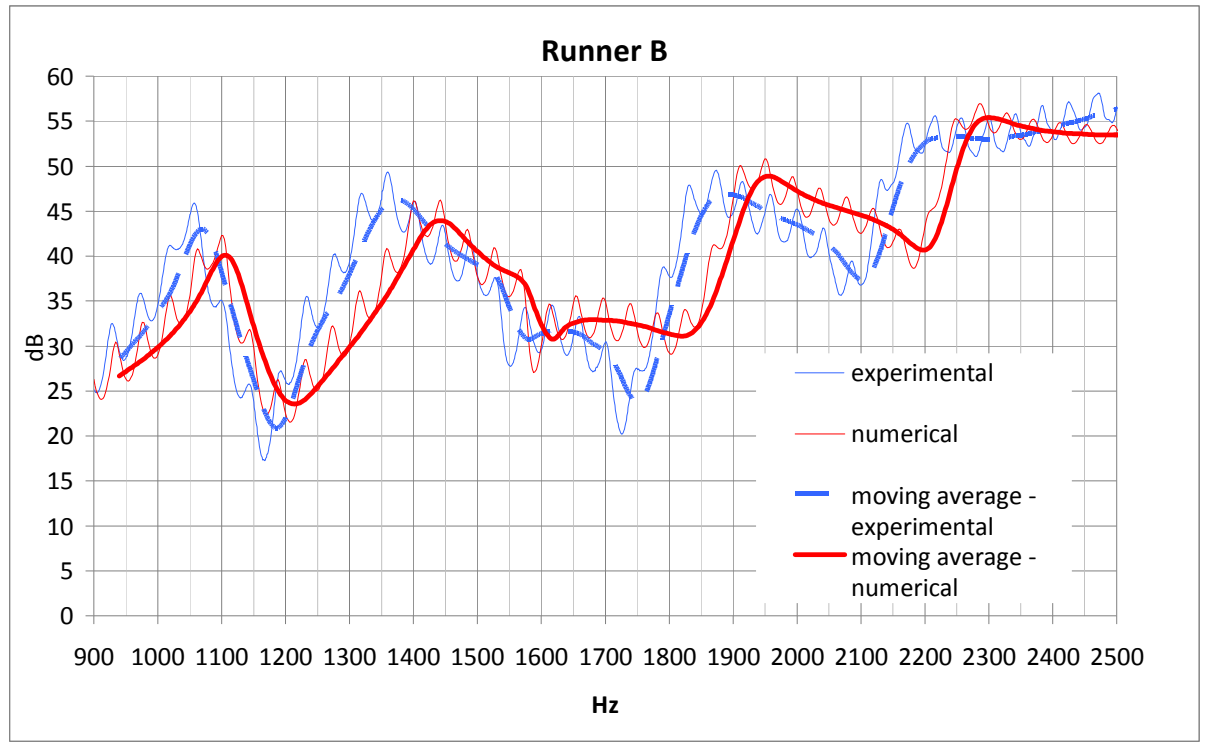

Fig. (17). Numerical and experimental acoustic pressure at the runner B of the manifold. 


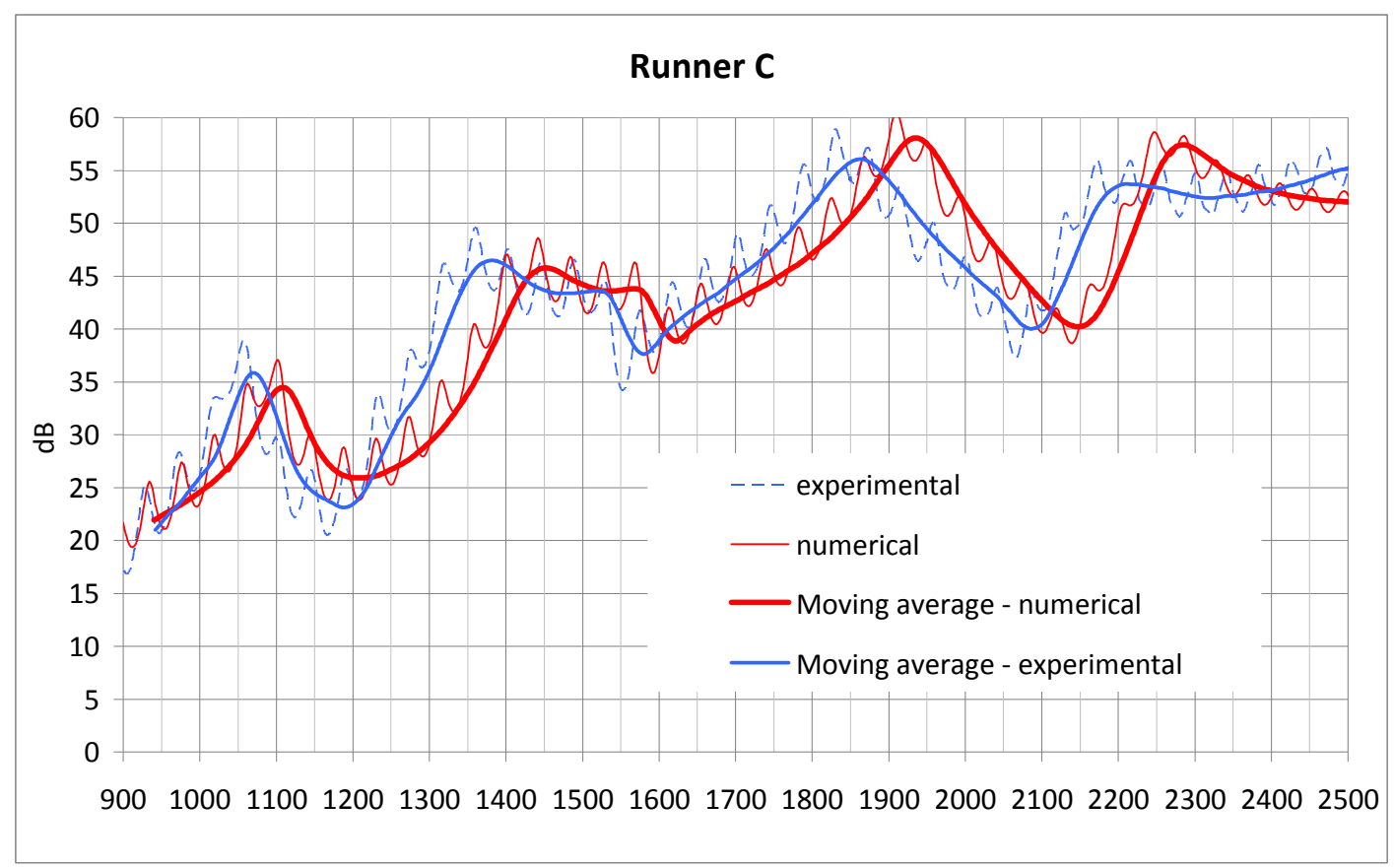

Fig. (18). Numerical and experimental acoustic pressure at the runner $\mathrm{C}$ of the manifold.

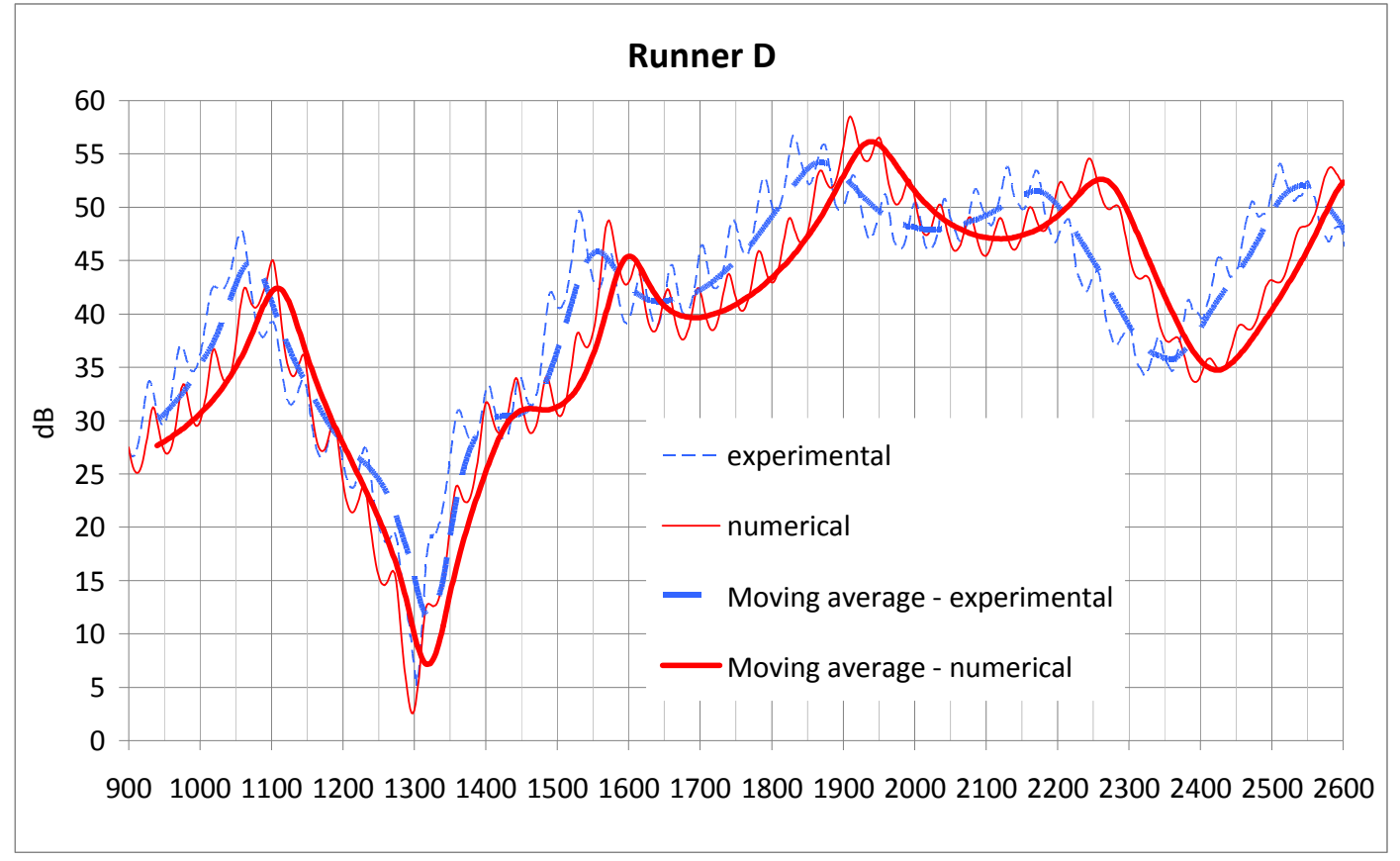

Fig. (19). Numerical and experimental acoustic pressure at the runner D of the manifold.

runner A-D and the pressure at position " $R$ ", in the same frequency range previously considered: such ratio is enhanced in correspondence of the manifold eigenfrequencies. In Fig. (20) the eigenfrequencies obtained by a numerical modal analysis are added too.

Actually, the frequency response function, calculated as the ratio between experimental acoustic pressures at respectively the runner A-D and the manifold exit " $R$ " suffer from a slight approximation due to the fact that the microphone "Ref", due to its relative position respect to the rubber tube and manifold, does not measure the only signal coming out from the source but also the feedback produced by the manifold (noise scatter due to the obstacle provided by the manifold and manifold emission form the opening " $R$ ").

One of the mode shapes (that at $1174 \mathrm{~Hz}$ ), obtained by an FEM modal analysis (using again Virtual. Lab) is shown in Fig. (22).

In Table 1 the eigenfrequencies obtained by forced response analysis, experimental analysis and modal analysis are compared, showing an acceptable degree of relative discrepancy but for the non negligible difference between the second eigenfrequency coming from the forced response analysis and the modal analysis. 


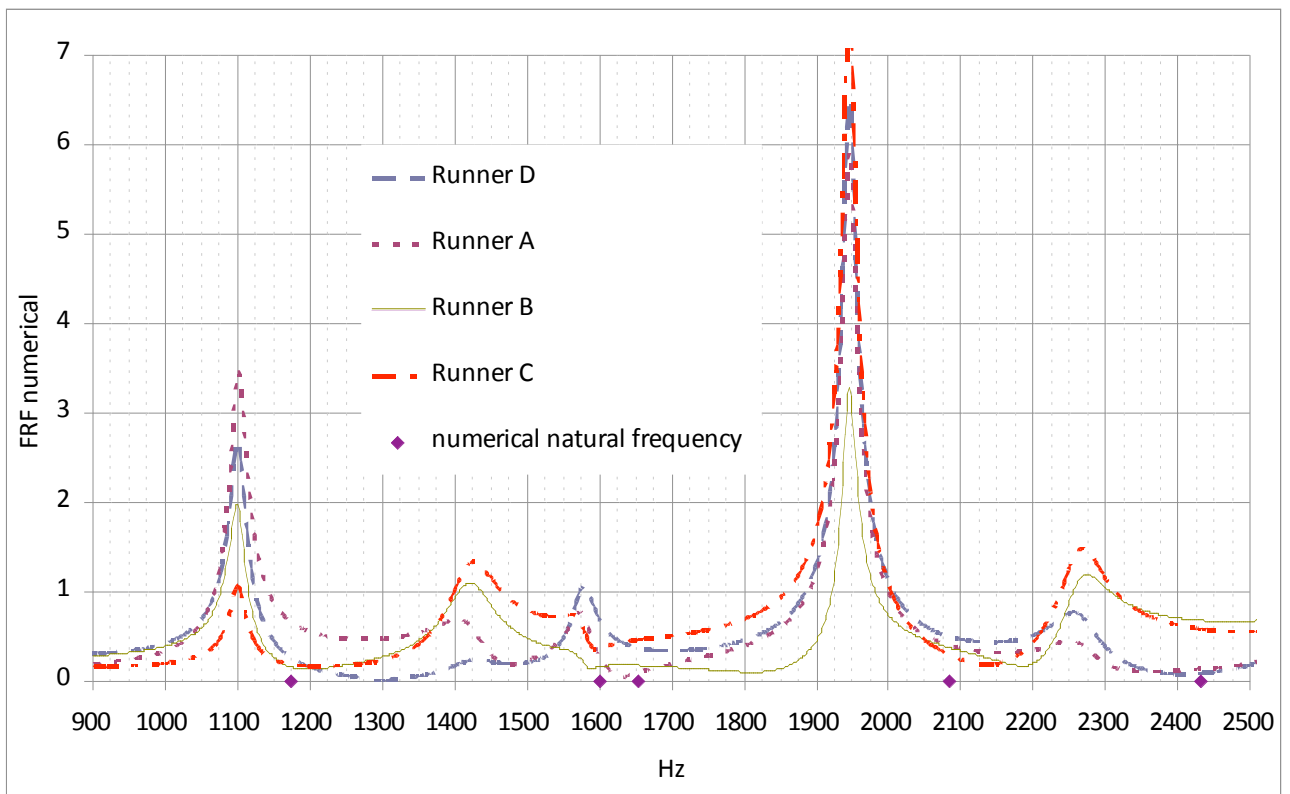

Fig. (20). Ratios between numerical acoustic pressures at the four runner A-D and the pressure at position "R". The eigenfrequencies obtained by a modal analysis are also highlighted.

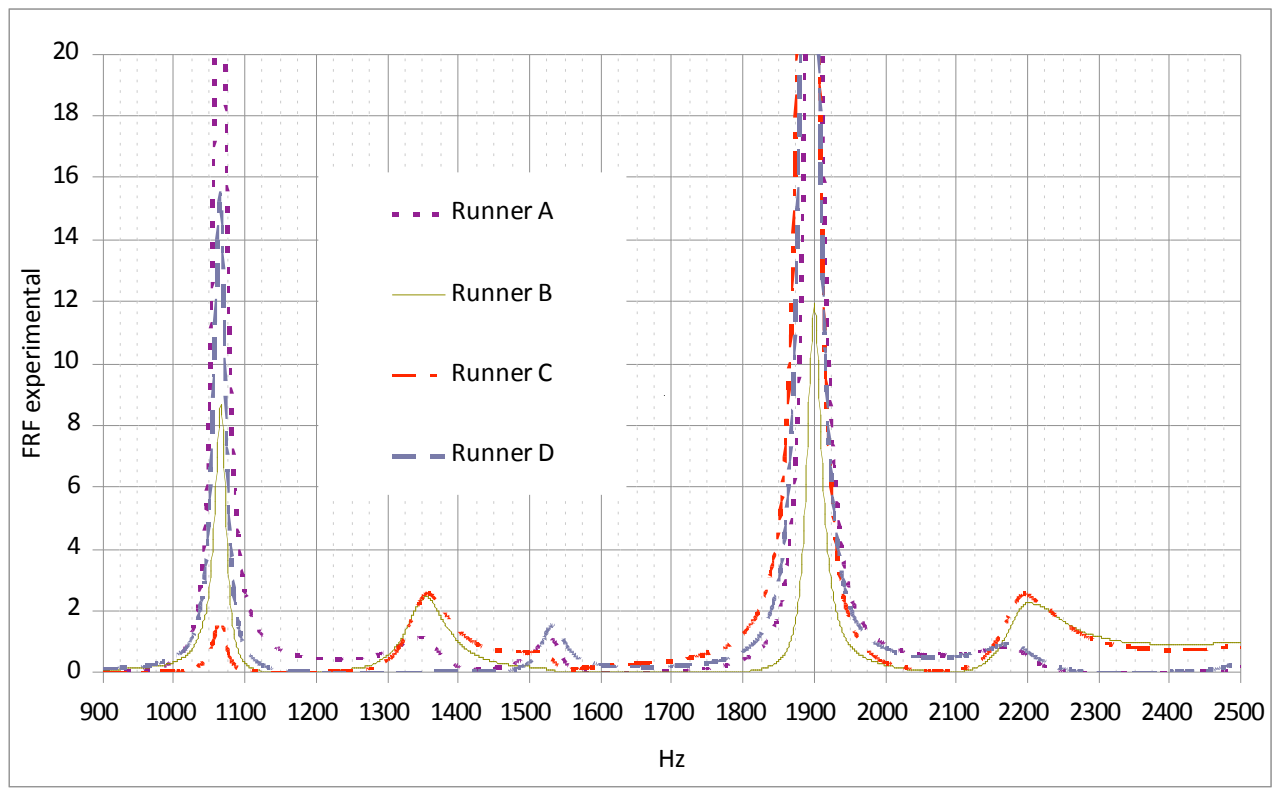

Fig. (21). Ratios between experimental acoustic pressures at the four runner A-D and the pressure at position "R".

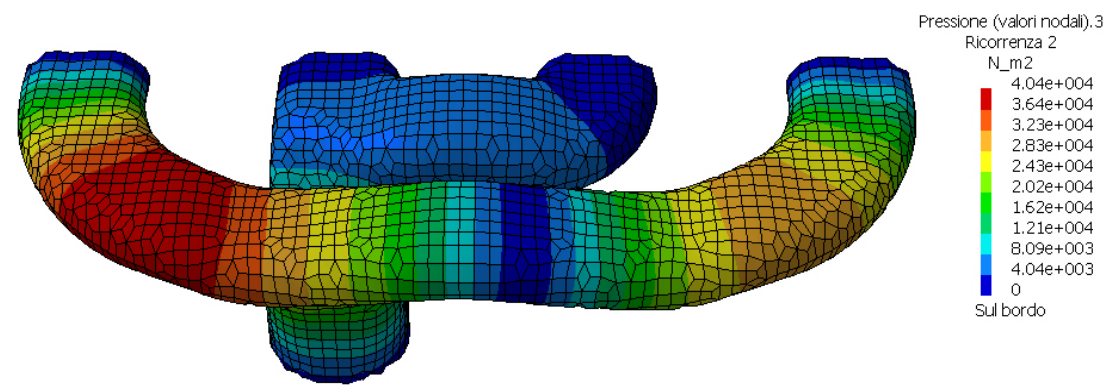

Fig. (22). Mode shape at $1174 \mathrm{~Hz}$. 
Table 1. Eigenfrequencies Obtained in Different Ways and Relative Error Evaluation

\begin{tabular}{|c|c|c|c|c|}
\hline Experimental & $\begin{array}{c}\text { Numerical } \\
\text { (forced response) }\end{array}$ & $\begin{array}{c}\text { Numerical } \\
\text { (modal analysis) }\end{array}$ & $\begin{array}{c}\text { \% Error } \\
\text { (forced response vs. modal analysis) }\end{array}$ & $\begin{array}{c}\text { \% Error } \\
\text { (experimental vs. forced response) }\end{array}$ \\
\hline \hline $1067 \mathrm{~Hz}$ & 1100 & 1174 & 6.3 & 3.0 \\
\hline 1359 & 1430 & 1600 & $\mathbf{1 0 . 6}$ & 5.0 \\
\hline 1533 & 1580 & 1653 & 4.4 & 3.0 \\
\hline 1900 & 1946 & 2082 & 6.5 & 2.4 \\
\hline 2190 & 2270 & 2431 & 6.6 & 3.5 \\
\hline
\end{tabular}

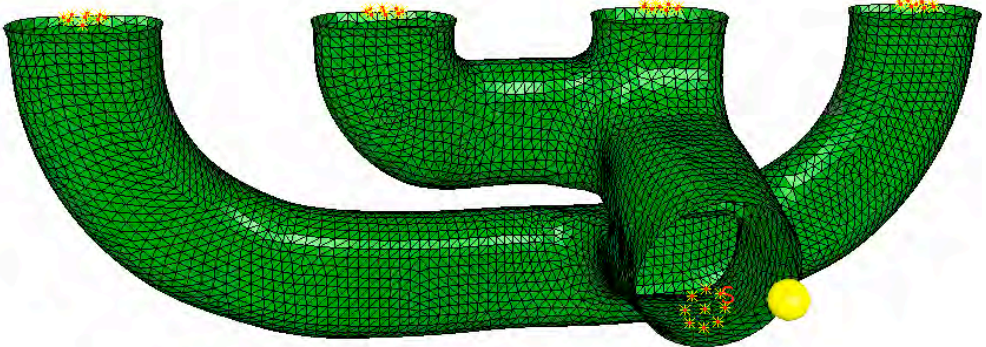

Fig. (23). IBEM model of exhaust manifold with an equivalent point source.

\section{IBEM ANALYSIS OF THE EXHAUST MANIFOLD WITHOUT EXPLICIT ACOUSTIC SOURCE MODEL- ING}

With a certain level of approximation, it is possible to use the pressure measurements provided by the microphone "Ref" in order to replace the explicit model of the acoustic source with an equivalent point source (monopole), able to generate the same signal recorded by "Ref" (Fig. 23). Actually this microphone is also slightly affected by the manifold acoustic emission but such effect is neglected in our analysis.

Using the following frequency dependent expression for the monopole amplitude $\mathrm{A}\left[\mathrm{kg} / \mathrm{sec}^{2}\right]$ :
$A(f)=50000 * \exp (-0,001 f)$

it is possible to impose the consistent (with experimental measurements) monopole volume velocity $\mathrm{Q}\left[\mathrm{m}^{3} / \mathrm{sec}\right]$

$\mathrm{Q}=(4 \pi \mathrm{A}) /(\mathrm{ipck})$

( $\mathrm{i}=$ imaginary unit, $\rho=$ air density, $\mathrm{c}=$ sound speed, $\mathrm{k}=$ wave number)

and get a satisfactory correlation between numerical and experimental pressures at the four runner A-D (Figs. 24-27). The excellent agreement is particularly evident considering the linear (and not logarithmic) scale used for the pressure representation (the representation with the pressure exp-

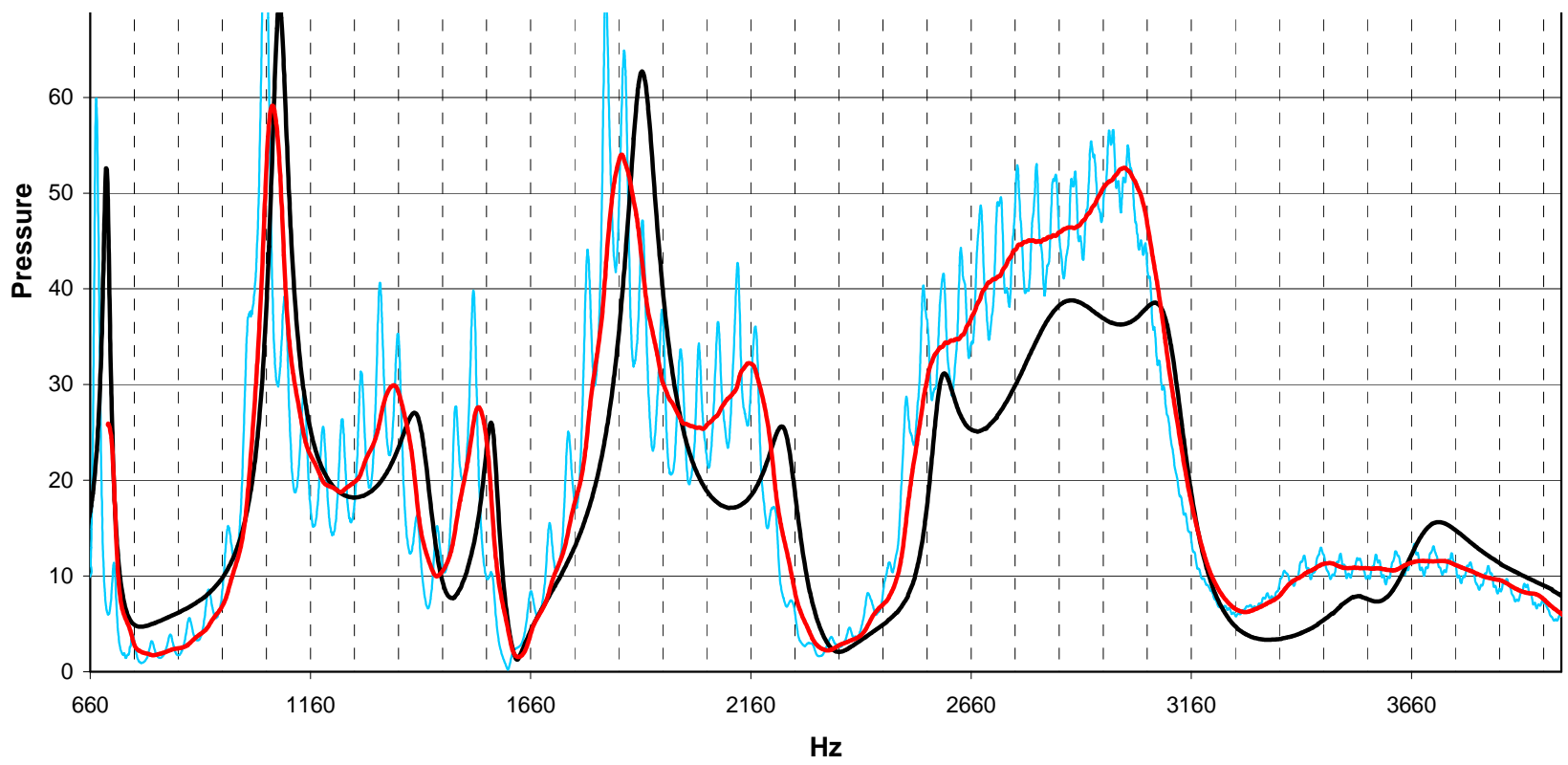

Fig. (24). Numerical (black line) and experimental (red line) acoustic pressure [Pa] at the runner A. 


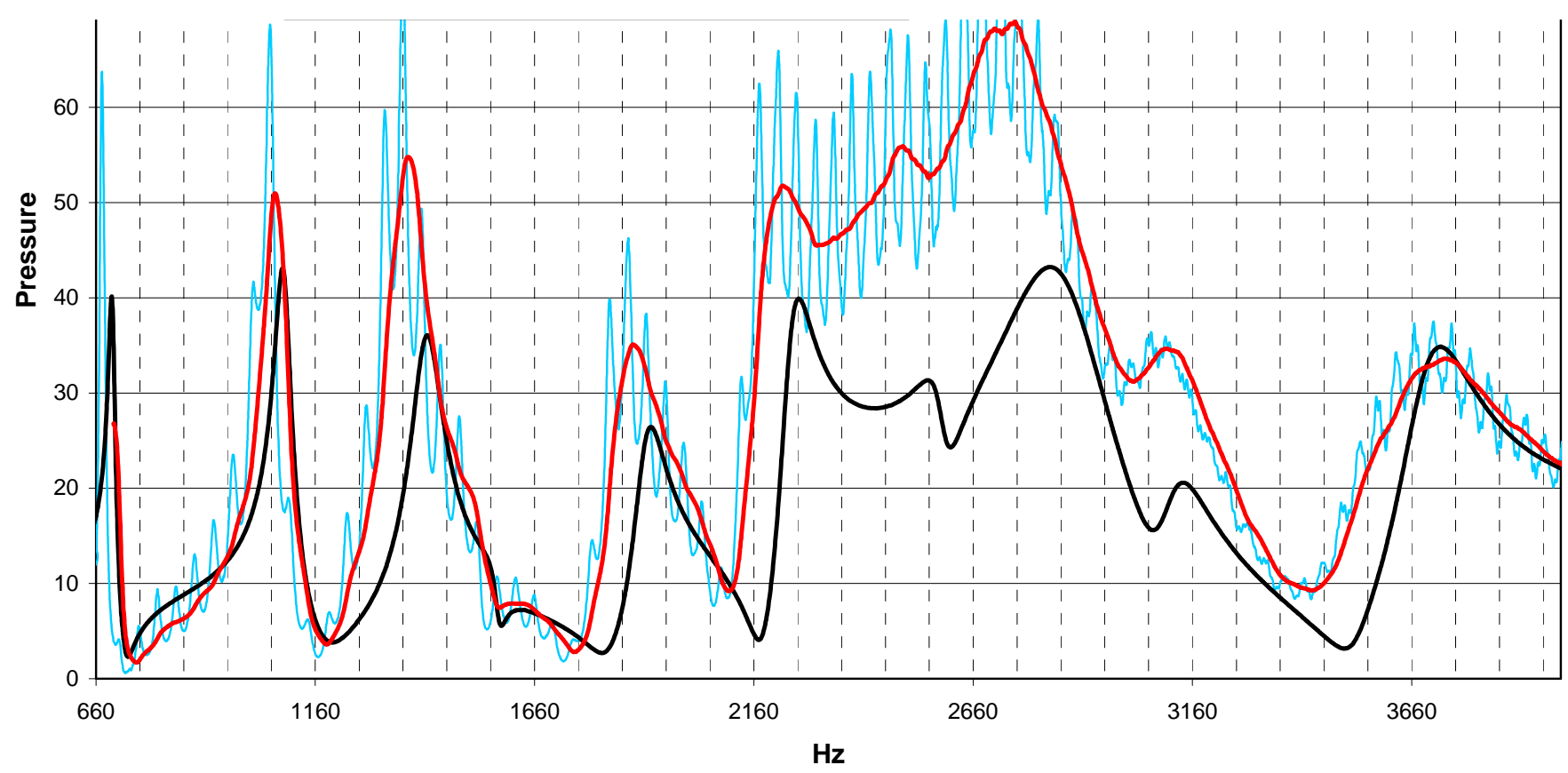

Fig. (25). Numerical (black line) and experimental (red line) acoustic pressure [Pa] at the runner B.

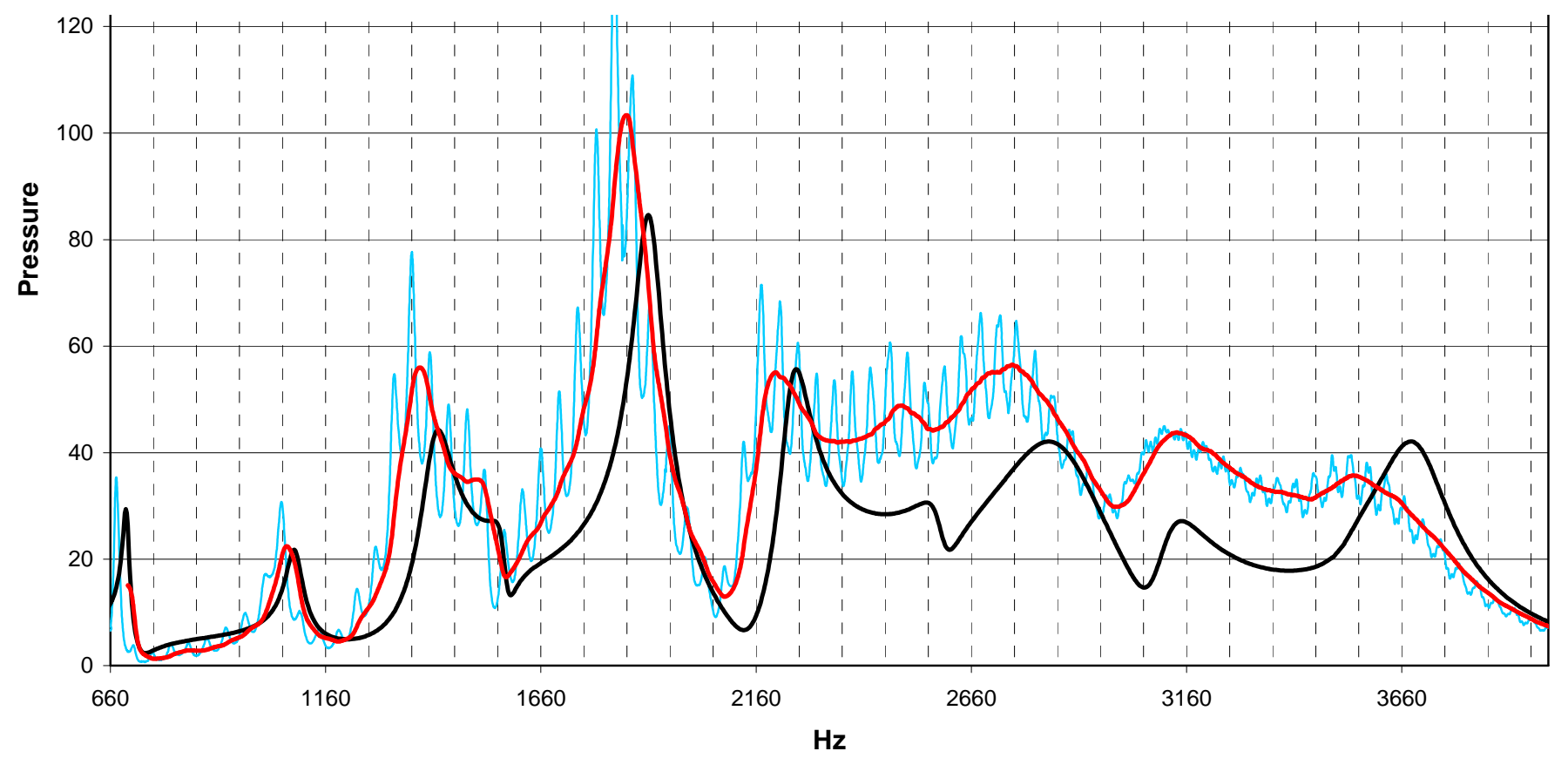

Fig. (26). Numerical (black line) and experimental (red line) acoustic pressure $[\mathrm{Pa}]$ at the runner $\mathrm{C}$.

ressed in $\mathrm{dB}$ would clearly show two curves almost overlapped). This time the moving average is only needed for the experimental curve because in the numerical analysis the oscillations caused by the rubber tube are not present.

\section{CONCLUSIONS}

This work has been developed by the following steps: experimental analysis in anechoic room, where the acoustic 


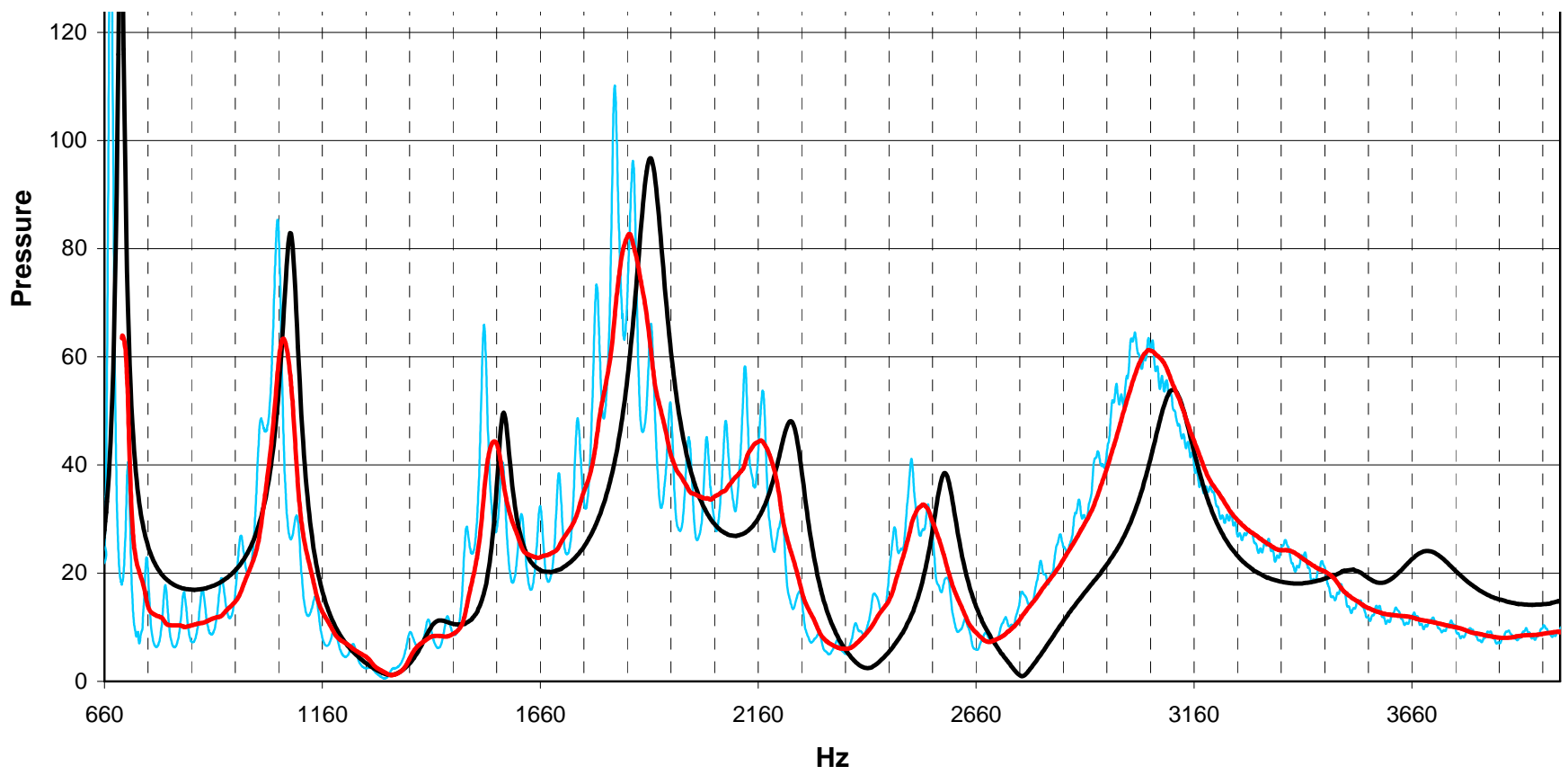

Fig. (27). Numerical (black line) and experimental (red line) acoustic pressure $[\mathrm{Pa}]$ at the runner D.

noise radiated through a simple tube (calibration test) or through the manifold is measured; a numerical analysis where IBEM is adopted to simulate the experiments and FEM is adopted for the manifold modal analysis; postprocessing activity to assess the numerical-experimental correlation.

The explicit modelling of the acoustic source rubber tube is clearly not needed in practical application but allow the assessment of the tube dynamic influence on the signal generation and shows the importance of a proper impedance boundary condition setting.

The IBEM approach for the acoustic radiation assessment of car components turn out to be particularly efficient, providing an appealing alternative to FEM: a detailed comparison between the two approaches is provided in [5].

\section{ACKNOWLEDGEMENT}

The authors acknowledge the FIAT company "Elasis" in Pomigliano D'Arco (Naples)-Italy contribution for the experimental campaign in anechoic room.

\section{REFERENCES}

[1] T. Wang, F.Q. Zhao, R. Zhang, and L. Qi, "Optimization design method of noise control on fine-pitch gear", Open Mech. Eng. J., vol. 5, pp. 103-107, 2011.

[2] D. Siano, and E.F. Corcione, "FE fluid-structure interaction/experimental transmission loss factor comparison of an exhaust system", In: Proceedings 7th International Conference on Engines for Automobile - ICE2005, 2005.

[3] D. Siano, "Three dimensional/one dimensional numerical correlation study of a three-pass perforated tube", J. Simul. Model. Pract. Th., 2010. doi: 10.1016/j.simpat.2010.04.005.
[4] T.C. Lim, "Automotive panel noise contribution modeling based on finite element and measured structural-acoustic spectra", Appl. Acoust., vol. 60, pp. 505-519, 2000.

[5] R. Citarella, L. Federico, and A. Cicatiello, "Modal acoustic transfer vector approach in a FEM-BEM vibro-acoustic analysis", Eng. Anal. Bound. Elem., vol. 31, pp. 248-258, 2007.

[6] A.R. Mohanty, B.D. St. Pierre, and P. Suruli-Narayanasami, "Structure-born noise reduction in a truck cab interior using numerical techniques", Appl. Acoust., vol. 59, pp. 1-17, 2000.

[7] S. Kopuz, and N. Lalor, "Analysis of interior acoustic fields using the finite element method and the boundary element method", Appl. Acoust., vol. 45, pp. 193-210, 1995.

[8] S. Kopuz, Y.S. Unlusoy, and M. Caliskan, "Integrated FEM/BEM approach to the dynamic and acoustic analysis of plate structures", Eng. Anal. Bound. Elem., vol. 17, pp. 269-277, 1996.

[9] S. Glaser, T. Hoenstenin, L. Kandathil, W.W. Kraft, M. Kushida, and S. Tousi, "Acoustical optimization of underhood plastic components", SAE Technical Paper 980732, International Congress and Exposition, 1998.

[10] C.K. Song, J.K. Hwang, J.M. Lee, and J.K. Hedrick, "Active vibration control for structural-acoustic coupling system of a 3-D vehicle cabin model", J. Sound Vib., vol. 267, pp. 851-865, 2003.

[11] S.H. Kim, and J.M. Lee, "A practical method for noise reduction in a vehicle passenger compartment", J. Vib. Acoust., vol. 120, pp. 199-205, 1998.

[12] A.S. Sarigul, and Z. Kiral, "Interior acoustics of a truck cabin with hard and impedance surfaces", Eng. Anal. Bound. Elem., vol. 23, pp. 769-775, 1999.

[13] L.R. Molisani, R.A. Burdisso and D. Tsihlas, "A coupled tire structure/acoustic cavity model”, Int. J. Solids Struct., vol. 40, pp. 5125-5138, 2003.

[14] G.J. Kim, K.R. Holland, and N. Lalor, "Identification of the airborne component of tire-induced vehicle interior noise", Appl. Acoust., vol. 51, pp. 141-156, 1997.

[15] J. Hadamard, "Lectures on cauchy's problem in linear partial differential equations", New Haven: Yale University Press, 1923.

[16] M. Guiggiani, and A. Gigante, "A general algorithm for multidimensional Cauchy principal value integrals in the boundary element method", J. Appl. Mech., Trans. ASME, vol. 57, pp. 907$915,1990$. 
[17] L. Cremer, and M. Heckl, "Körper schall: physikalische Grundlagen und technische Anwendungen", Springer Verlag, 1982.

[18] O. von Estorff, J.P. Coyette, and J.L. Migeot, "Governing formulations of the BEM in acoustics", In: O. von Estorff, Ed., Boundary Elements in Acoustics - Advances and Applications, WIT Press, Southampton, 2000.

[19] M.A. Hamdi, "A variational formulation by integral equations for the solution of the Helmholtz equation with mixed boundary conditions" (in French), Compte-rendus Académie des Sciences, vol. 292, 1981.

[20] J.L. Migeot, K. Meerbergen, C. Lecomte, and J.P. Coyette. "Practical implementation issues of acoustic BEM". In: O. von
Estorff, Ed., Boundary Elements in Acoustics - Advances and Applications. WIT Press, Southampton, 2000.

[21] A.F. Seybert, R.A. Seman, and M.D. Lattuca, "Boundary element prediction of sound propagation in ducts containing bulk absorbing materials", Trans. ASME, vol. 120, pp. 976-981, 1998.

[22] C. Vicari, and M. Onorato, "A BE model for the analysis of the effects of seats in the passenger compartment acoustic behaviour", SAE Paper 1999-01-1970, In: Noise and Vibration Conference \& Exposition, 1999.

[23] LMS Virtual. Lab Rev 8B Theoretical Manual, LMS International nv, Leuven, Belgium, 2008.

(C) Citarella and Landi; Licensee Bentham Open.

This is an open access article licensed under the terms of the Creative Commons Attribution Non-Commercial License (http: //creativecommons.org/licenses/by$\mathrm{nc} / 3.0 /$ ), which permits unrestricted, non-commercial use, distribution and reproduction in any medium, provided the work is properly cited. 